\title{
Management of pediatric cardiac transplantation candidates with pulmonary hypertension and high pulmonary vascular resistance
}

\author{
Kahraman Yakut ${ }^{1 \oplus}$, Birgül Varan $^{1 \oplus}$, İlkay Erdoğan ${ }^{1 \oplus}$, Nimet Cindik $^{20}$, \\ Mahmut Gökdemir ${ }^{2 \oplus}$, Ayten Gümüsş ${ }^{1 \oplus}$ N. Kürşad Tokel ${ }^{1 \oplus}$, Atilla Sezgin ${ }^{3 \oplus}$ \\ Departments of ${ }^{1}$ Pediatric Cardiology and ${ }^{3}$ Cardiovascular Surgery, Başkent University Faculty of Medicine, Ankara; ${ }^{2}$ Department of \\ Pediatric Cardiology, Başkent University Faculty of Medicine, Konya, Turkey.
}

\begin{abstract}
Background and objectives. Right ventricular failure is an important cause of mortality and morbidity after orthotopic heart transplantation (OHT). The right ventricle of the donor may fail to accommodate to the high pulmonary vascular resistance (PVR) of the recipient. Pulmonary hypertension (PH) due to chronic heart failure with PVRi $>4$ Wood units. $\mathrm{m}^{2}$, transpulmonary gradient $>15 \mathrm{mmHg}$ adversely affect the outcome of OHT. In this study we aimed to evaluate management strategies in our pediatric cardiac transplantation candidates with PH and high PVR prior to OHT.

Method. Twenty-six cardiac transplantation candidates (age: $10.2 \pm 4.6,1-17$ years) underwent cardiac catheterization for the determination of PVR and pulmonary arterial pressure. They were admitted to the hospital and received 1-3 days of intravenous (IV) vasodilator therapy; $0.5-3 \mu \mathrm{g} / \mathrm{kg} / \mathrm{min}$ nitroglyserin and/or 0.5-3 $\mu \mathrm{g} / \mathrm{kg} / \mathrm{min}$ nitroprusside, $5-15 \mu \mathrm{g} / \mathrm{kg} / \mathrm{min}$ dobutamin and/or dopamin to keep systolic blood pressure above $80 \mathrm{mmHg}$.
\end{abstract}

Results. Thirteen patients had dilated cardiomyopathy (CMP), 11 had restrictive CMP, one had hypertrophic CMP and one had congenital heart disease (CHD). Nineteen of the 26 patients underwent OHT.

Mean pulmonary arterial pressure of the patients ranged between 11 and $82 \mathrm{mmHg}(30.4 \pm 16 \mathrm{mmHg})$ and PVRi between 0.41-21.4 Wood units. $\mathrm{m}^{2}$ (5.3 \pm 5.7$)$. Nine patients had PVRi above 4 Wood units.m². Six of these patients had IV treatment for longer than three days and some received specific anti-PH treatment. Eventually they underwent a pulmonary vasoreactivity test with IV iloprost and six had PVRi $<4$ Wood units.m². Five of them underwent OHT.

Conclusion. Cardiac transplantation candidates with PH and high PVR should be evaluated after conditioning with vasodilator and inotropic treatment. Specific treatment for PH and vasoreactivity testing may help selected patients reenter the transplantation list.

Key words: cardiac transplantation, pulmonary hypertension, pulmonary vascular resistance, right ventricular failure.

Advanced heart failure patients considered for heart transplantation frequently have Pulmonary hypertension $(\mathrm{PH})$. Patients with restrictive and dilated cardiomyopathy (CMP), who have chronic heart failure with elevated

Birgül Varan

birgulv@hotmail.com

Received 5th December 2019, accepted 3rd February 2020. filling pressures are especially under risk. Severe $\mathrm{PH}$ is considered a contraindication for heart transplantation as $\mathrm{PH}$ leads to right ventricular dysfunction. Right ventricular failure is an important cause of mortality and morbidity after orthotopic heart transplantation $(\mathrm{OHT}) \cdot{ }^{1-3}$

The right ventricle of the donor may fail to accommodate the high PVR of the recipient. 
Preoperative pulmonary artery pressure and PVR were found to affect mortality after heart transplantation. ${ }^{2-7} \quad$ Pulmonary hypertension due to chronic heart failure with PVRi $>4$ Wood units. $\mathrm{m}^{2}$, transpulmonary gradient $>15 \mathrm{mmHg}$ adversely affect the outcome of OHT. Thus patients are evaluated with cardiac catheterization before consideration for cardiac transplantation. Several drugs are used before and/or during cardiac catheterization to decrease pulmonary arterial pressure and pulmonary vascular resistance (PVR) and to test the reversibility of high PVR..$^{3-5,8-11}$

We aimed to evaluate management strategies in our pediatric cardiac transplantation candidates with PH and high PVR prior to OHT.

\section{Material and Methods}

Twenty-six cardiac transplantation candidates (age: $10.2 \pm 4.6$, range 1-17 years) underwent cardiac catheterization for determination of PVR and pulmonary arterial pressure. They were admitted to the hospital and received 1-3 days of IV vasodilator therapy; $0.5-3 \mu \mathrm{g} /$ $\mathrm{kg} / \mathrm{min}$ nitroglyserin and/or $0.5-3 \mu \mathrm{g} / \mathrm{kg} / \mathrm{min}$ nitroprusside, $5-15 \mu \mathrm{g} / \mathrm{kg} / \mathrm{min}$ dobutamin and/ or dopamin to keep systolic blood pressure above $80 \mathrm{mmHg}$, in addition to their usual drugs such as furocemide, spironolactone, angiotensin converting enzyme inhibitors and beta blockers. All patients who had $\mathrm{PH}$ and high PVRi underwent a pulmonary vasoreactivity test with IV iloprost. Patients with PH and PVRi greater than 4 Wood units. $\mathrm{m}^{2}$ after vasoreactivity test received additional therapy including IV vasodilator and inotropic treatment for longer than three days. Additionally, five patients received specific anti-PH therapy. This study was approved by the ethics committee of our university (28/05/2019-KA19/199).

\section{Results}

Thirteen patients had dilated CMP, 11 had restrictive $\mathrm{CMP}$, one had hypertrophic CMP and one had severe left ventricular failure years after a Rastelli operation for transposition of great arteries, ventricular septal defect and pulmonary stenosis. Nineteen of the 26 patients underwent OHT. Mean pulmonary arterial pressure of the patients ranged between 11 and $82 \mathrm{mmHg}(30.4 \pm 16 \mathrm{mmHg})$, PVRi between 0.41-21.4 Wood units.m ${ }^{2}(5.3 \pm 5.7)$. Nine patients had PVRi above 4 Wood units. $\mathrm{m}^{2}$. Six of these patients were reevaluated after receiving IV treatment for longer than three days. Additionally, five patients received specific anti-PH drugs before reevaluation. Patient 1 received sildenafil for 7 days besides intravenous inotropic and vasodilator treatment of 10 days. Patient 4 received bosentan for one month. Patient 7 received bosentan for one week which was stopped due to elevation of liver enzyme levels. She received inhaled iloprost for four months and was admitted to the hospital 7 days before cardiac catheterization and was put on dobutamin and nitroglyserin. IV iloprost was started 24 hours before catheterization. Patient 8 received inhaled iloprost for six months and bosentan for five months, and was admitted to the hospital three days before cardiac catheterization and was put on dobutamin and nitroglyserin. Patient 9 was put on bosentan for two months, and was admitted to the hospital 10 days before cardiac catheterization and was put on dobutamin, nitroglyserin, and nitroprusside. He also received IV iloprost for 24 hours before catheterization.

Eventually all underwent pulmonary vasoreactivity test with IV iloprost. Six patients had PVRi $<4$ Wood units.m². Five of these underwent OHT. The four-year-old patient (Patient 3) with restrictive CMP had a PVRi of 8.8 Wood units. ${ }^{2}$. After OHT PVRi was 5.27 Wood units.m². Despite bosentan and inhaled iloprost treatment he died due to right heart failure three months after transplantation. The course of the other five patients was uneventful. The hemodynamic variables and clinical course of these 9 patients are summarized in Table I.

Informed consent was obtained from all individual participants included in the study. 


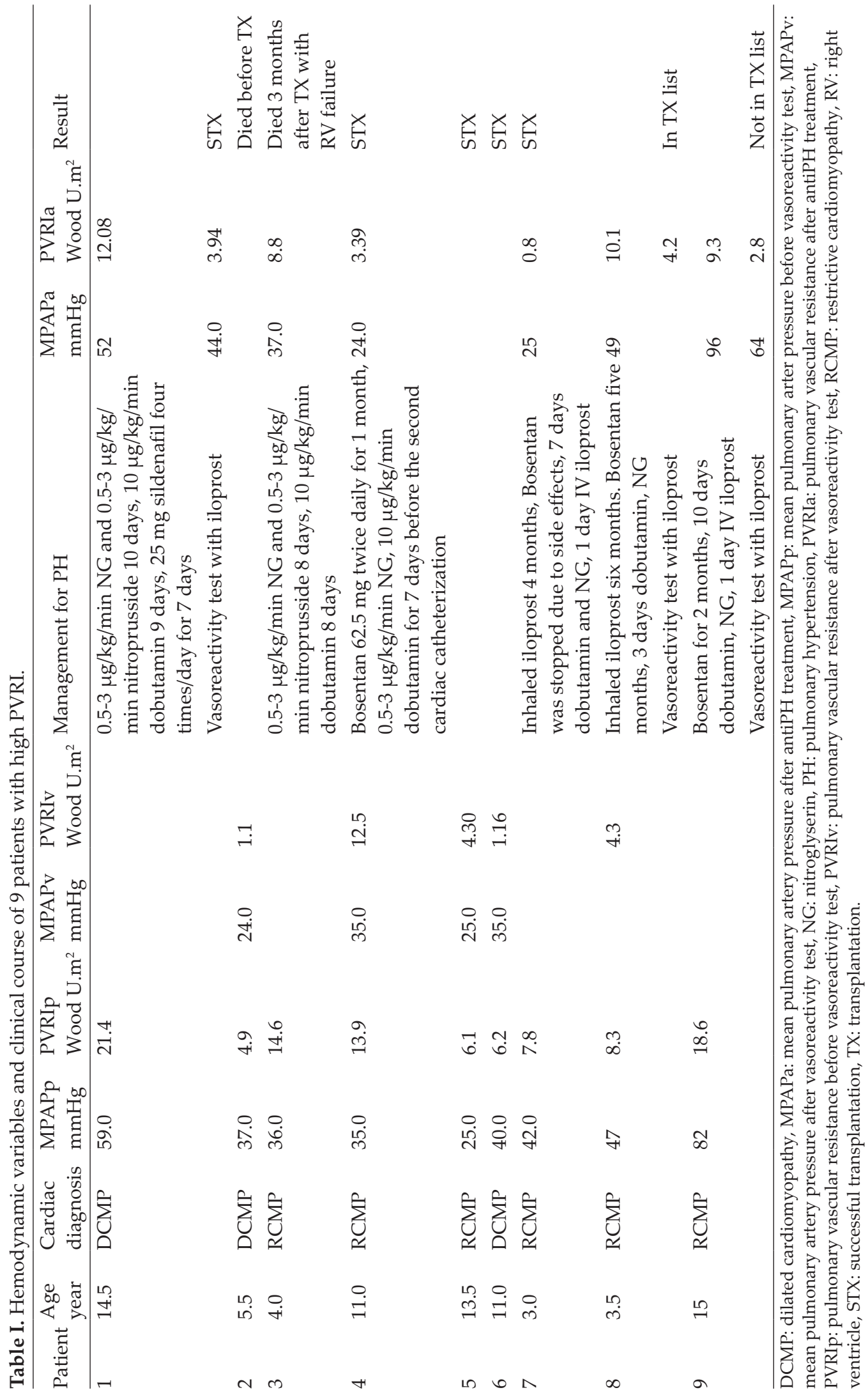




\section{Discussion}

Pulmonary hypertension and right ventricular failure is an important cause of mortality and morbidity after OHT. ${ }^{1-7}$ Elevated PVRi is generally considered to be a contraindication for heart transplantation in most centers. ${ }^{2,3,11}$ In some studies, it has been reported that high PVRi should not be a contraindication and this is not related to mortality for OHT. ${ }^{12,13}$ Chiu et al. ${ }^{12}$ reported that survival was similar in both unmatched and propensity-matched analyses of groups of patients using either a threshold of PVRI $\geq 6$ or PVRI $\geq 9$ WUx $\mathrm{m}^{2}$. The evolving management of right ventricular dysfunction following OHT, use of mechanical circulatory support and targeted therapy for pulmonary hypertension may allow survival of transplanted patients with high PVRI. In spite of favorable results, concerns about adverse outcome of pre-transplantation pulmonary hypertension continues. Costard-Jackle et al. ${ }^{4}$ reported a $3.3 \%$ mortality rate due to $\mathrm{PH}$ or right ventricular failure in 301 patients which was responsible for $26 \%$ of deaths within 90 days after OHT. A pediatric study reported by Addonizio et al. ${ }^{14}$ correlated outcomes of pediatric patients with various levels of PVRi. Pulmonary vascular resistance index above 6 Wood units. $\mathrm{m}^{2}$ was related with poor survival due to right ventricular failure. Gajarski et al. ${ }^{15}$ compared their results in pediatric heart transplant recipients with a mean PVRi of $11.5 \pm$ 3.5 Wood units. $\mathrm{m}^{2}$ with those having mean PVRi of $2.3 \pm 0.4$ Wood units. $\mathrm{m}^{2}$. After prostaglandin $\mathrm{E}_{1}$ infusion as a vasodilator, PVRi decreased to $3.9 \pm 0.9$ Wood units. $\mathrm{m}^{2}$ in those with high PVRi. They concluded that the reactivity of the pulmonary vascular bed rather than the absolute measure of the PVR correlated with outcome as the mortality was similar in two groups.

Patients with chronic heart failure may have $\mathrm{PH}$ resulting from several reasons. Increased left ventricular end-diastolic pressure causing increased left atrial and increased pulmonary capillary pressures eventually leads to high pulmonary arterial pressure. Pulmonary hypertension due to heart failure was classically thought to develop as a passive consequence of high filling pressures of the left ventricle. ${ }^{16-19}$ However pulmonary pressures and PVR may remain high after heart transplantation for a varying time and may decrease gradually.,11 This suggests the occurrence of structural changes in pulmonary vessels. Delgado et al. ${ }^{20}$ demonstrated an increase in the medial thickness of the muscular pulmonary arteries of patients dying early after OHT. In patients with congestive heart failure persistent elevation of left ventricular end-diastolic pressure leads to passive pulmonary venous congestion and reactive pulmonary vasoconstriction. ${ }^{16,17,21}$ Persistent elevation of pulmonary capillary pressure due to increased left ventricular filling pressure may result in histological changes in the pulmonary vasculature. ${ }^{16-19,22}$ At the beginning PVR is reversible with pulmonary vasodilators until prolonged pulmonary venous congestion causes remodelling of the pulmonary arterial wall with abnormalities of the elastic fibers, intimal fibrosis and medial hypertrophy. At this time $\mathrm{PH}$ may be defined as fixed as it is resistant to pulmonary vasodilators. Ortiz et al. ${ }^{23}$ have investigated the evolution of right heart pressures in an adult series in the first year after heart transplantation with respect to background cardiac disease. The right heart pressures showed an important decrease in the first days after heart transplantation with stabilization by the third month but without returning to normal. However, the PVRi in this series was less than 4 Wood units.m². We applied intravenous drugs for deloading and for decreasing afterload to optimize the hemodynamics before evaluating the PVR. This conditioning is important as pulmonary edema and systemic vasoconstriction may adversely affect pulmonary pressure and cardiac index. Several reports in pediatric and adult patients have stated that intensive treatment with inotropes, vasodilators and in some cases left ventricular assist device can lower PVR and allow for transplantation. . $11,24,25$ Mahajan et al. ${ }^{9}$ reported a series of 21 adult patients with dilated CMP with persistent moderate to severe $\mathrm{PH}$ despite intravenous medical therapy. All 
patients received 1 to 3 days of IV cardiac drug therapy including vasodilators, inotropes and diuretics with the goal of optimizing hemodynamics with maximally tolerated doses of IV vasodilators. Twenty-one patients who had persistent moderate to severe $\mathrm{PH}$ underwent testing with $100 \%$ oxygen and inhaled nitric oxide. Nitric oxide caused a more significant decrease in pulmonary arterial pressure and PVRi than oxygen. Nine of the patients had PVR decreased below 4 Wood units and were included in the transplantation list.

Several drugs have been used for testing the reversibility of high PVR. Sablotzki et al. ${ }^{26}$ investigated hemodynamic effects of inhaled aerosolized iloprost and inhaled nitric oxide in heart transplant candidates with elevated PVR. They showed that inhaled iloprost induced pulmonary vasodilation greater than the effects of 10 and $30 \mathrm{ppm}$ nitric oxide and they recommended iloprost as a routine screening drug for vascular reactivity in heart transplantation candidates. We used intravenous iloprost for this purpose. Adenosine was also successfully used by Haywood et al. ${ }^{8}$ for the reversal of pulmonary vasoconstriction in biventricular failure and was found to be superior to nitroprusside. In another study however adenosine was less effective with more side effects than inhaled nitric oxide in a group of patients with pulmonary arterial hypertension. ${ }^{27}$

Despite cautious treatment with vasodilators, inotropes and diuretics to optimize hemodynamics and to decrease pulmonary edema before evaluation of pulmonary arterial pressure and PVR some patients still have high PVR not allowing transplantation. Specific treatment for $\mathrm{PH}$ can further help to relist patients with high PVR. ${ }^{3,5,11,28,29}$ Kao et al. ${ }^{28}$ reported a 14 year-old patient with dilated CMP who was previously operated for aortic coarctation and ventricular septal defect in infancy. The patient had a PVRi of 27 Wood units. $\mathrm{m}^{2}$. After two months of continuous prostacyclin infusion of up to $14 \mathrm{ng} / \mathrm{kg} /$ min repeat cardiac catheterization revealed
PVRi of 3.7 Wood units.m². She underwent heart transplantation one month later with extracorporeal membrane oxygenation support for the first four days. Perez-Villa et al. ${ }^{29}$ reported one of the initial experiences with bosentan, an oral endothelin-receptor antagonist to overcome high pulmonary artery pressure and PVR in 7 patients who were considered ineligible for heart transplantation. After six weeks of bosentan therapy five of them had a PVR $<2.5$ Wood units and underwent successful heart transplantation.

The use of a left ventricular assist device (LVAD) has been proposed as an effective treatment for reducing PVRi in potential heart transplant candidate's refractory to medical vasodilator therapies.30,31 In current studies after LVAD implantation, the patients experienced a profound decrease in PVRi on follow-up cardiac catheterization. The resulting dramatic improvement in PVRi in a relatively short period of time allowed for successful OHT. ${ }^{25,32}$ In addition, the use of ventricular support devices help to avoid sudden loss of OHT candidates waiting for transplant. In our study, we showed that the patients with high pulmonary artery pressure and PVRi could be included in the waiting list after treatment with vasodilators, inotropes and diuretics. It was also possible to detect reversible PVR after vasodilator, inotropic and diuretic treatment. These therapies have been shown to reduce the incidence of right heart failure and potentially reduce the morbidity and mortality of posttransplantation right heart failure in single institution reports. ${ }^{3,33,34}$

Several studies showed that the current treatments after OHT decrease the contribution of PVRI elevation on right ventricular failure and early mortality. ${ }^{13,35}$ Improved management of $\mathrm{PH}$ and right ventricular dysfunction may have changed the relationship between PVR and post-transplant mortality.

In this study, the lack of comparative analysis due to the small number of patients was a limitation. Non-standardization of specific anti$\mathrm{PH}$ treatment was considered as a disadvantage. 
In conclusion cardiac transplantation candidates with PH and high PVR should be evaluated after conditioning with vasodilator and inotropic treatment. Specific treatment for $\mathrm{PH}$ and vasoreactivity testing may help selected patients reenter the transplantation list.

\section{REFERENCES}

1. Hosenpud JD, Bennett LE, Keck BM, Boucek MM, Novick RJ. The Registry of the International Society for Heart and Lung Transplantation: seventeenth official report-2000. J Heart Lung Tranplant 2000; 19: 909-931.

2. Hoskote A, Carter C, Rees P, Elliott M, Burch M, Brown K. Acute right ventricular failure after pediatric cardiac transplant: predictors and longterm outcome in current era of transplantation medicine. J Thorac Cardiovasc Surg 2010; 139: 146153.

3. Huang J, Trinkaus $\mathrm{K}$, Huddleston $\mathrm{CB}$, Mendeloff EN, Spray TL, Canter CE. Risk factors for primary graft failure after pediatric cardiac transplantation: importance of recipient and donor characteristics. J Heart Lung Transplant 2004; 23: 716-722.

4. Costard-Jäckle A, Fowler MB. Influence of preoperative pulmonary artery pressure on mortality after heart transplantation: testing of potential reversibility of pulmonary hypertension with nitroprusside is useful in defining a high risk group. J Am Coll Cardiol 1992; 19: 48-54.

5. Mancini D, Lietz K. Selection of cardiac transplantation candidates in 2010. Circulation 2010; 122: 173-183.

6. Muthialu N. Orthotopic heart transplantation in children. Asian Cardiovasc Thorac Ann 2018; 26: 277-284.

7. Lundgren J, Söderlund C, Rådegran G. Impact of postoperative pulmonary hypertension on outcome after heart transplantation. Scand Cardiovasc J 2017; 51: 172-181.

8. Haywood GA, Sneddon JF, Bashir Y, Jennison $\mathrm{SH}$, Gray HH, McKenna WJ. Adenosine infusion for the reversal of pulmonary vasoconstriction in biventricular failure: a good test but a poor therapy. Circulation 1992; 86: 896-902.

9. Mahajan A, Shabanie A, Varshney SM, Marijic J, Sopher MJ. Inhaled nitric oxide in the preoperative evaluation of pulmonary hypertension in heart transplant candidates. J Cardiothorac Vasc Anesth 2007; 21: 51-56.
10. Murali S, Uretsky BF, Reddy PS, Tokarczyk TR, Betschart AR. Reversibility of pulmonary hypertension in congestive heart failure patients evaluated for cardiac transplantation: comparative effects of various pharmacologic agents. Am Heart J 1991; 122: 1375-1381.

11. Daftari B, Alejos JC, Perens G. Initial experience with sildenafil, bosentan, and nitric oxide for pediatric cardiomyopathy patients with elevated pulmonary vascular resistance before and after orthotopic heart transplantation. J Transplant 2010; 2010: 656984.

12. Chiu P, Schaffer JM, Sheikh AY, et al. Elevated pretransplant pulmonary vascular resistance index does not predict mortality after isolated orthotopic heart transplantation in children: a retrospective analysis of the UNOS database. Pediatr Transplant 2015; 19: 623-633.

13. Richmond ME, Law YM, Das BB, et al; Pediatric Heart Transplant Study Investigators. Elevated pre-transplant pulmonary vascular resistance is not associated with mortality in children without congenital heart disease: a multicenter study. J Heart Lung Transplant 2015; 34: 448-456.

14. Addonizio LJ, Gersony WM, Robbins RC, et al. Elevated pulmonary vascular resistance and cardiac transplantation. Circulation 1987; 76(5 Pt 2): V52-V55.

15. Gajarski RJ, Towbin JA, Bricker JT, et al. Intermediate follow-up of pediatric heart transplant recipients with elevated pulmonary vascular resistance index. J Am Coll Cardiol 1994; 23: 1682-1687.

16. Rosenkranz S, Gibbs JS, Wachter R, De Marco T, Vonk-Noordegraaf A, Vachiéry JL. Left ventricular heart failure and pulmonary hypertension. Eur Heart J 2016; 37: 942-954.

17. Guazzi M, Naeije R. Pulmonary hypertension in heart failure: pathophysiology, pathobiology, and emerging clinical perspectives. J Am Coll Cardiol 2017; 69: 1718-1734.

18. Naeije R, Vanderpool R, Peacock A, Badagliacca $\mathrm{R}$ The right heart-pulmonary circulation unit: physiopathology. Heart Fail Clin 2018; 14: 237-245.

19. Galie N, Humbert M, Vachiery JL, et al; ESC Scientific Document Group. 2015 ESC/ERS Guidelines for the diagnosis and treatment of pulmonary hypertension: the Joint Task Force for the diagnosis and treatment of pulmonary hypertension of the European Society of Cardiology (ESC) and the European Respiratory Society (ERS): endorsed by: association for European Paediatric and Congenital Cardiology (AEPC), International Society for Heart and Lung Transplantation (ISHLT). Eur Heart J 2016; 37: 67119. 
20. Delgado JF, Conde E, Sanchez V, et al. Pulmonary vascular remodelling in pulmonary hypertension due to chronic heart failure. Eur J Heart Fail 2005; 7: 1011-1016.

21. Gazit AZ, Canter CE. Impact of pulmonary vascular resistances in heart transplantation for congenital heart disease. Curr Cardiol Rev 2011; 7: 59-66.

22. Guazzi M, Borlaug BA. Pulmonary hypertension due to left heart disease. Circulation 2012; 126: 975990.

23. Ortiz V, Martínez-Dolz L, Ten F, et al. Evolution of right cardiac pressures during the first year after heart transplantation. Transplant Proc 2007; 39: 2368-2371.

24. Bhat G, Costea A. Reversibility of medically unresponsive pulmonary hypertension with nesiritide in a cardiac transplant recipient. ASAIO J 2003; 49: 608-610.

25. Sato T, Seguchi O, Morikawa N, et al. A heart transplant candidate with severe pulmonary hypertension and extremely high pulmonary vascular resistance. J Artif Organs 2013; 16: 253-257.

26. Sablotzki A, Hentschel T, Gruenig E, et al. Hemodynamic effects of inhaled aerosolized iloprost and inhaled nitric oxide in heart transplant candidates with elevated pulmonary vascular resistance. Eur J Cardiothorac Surg 2002; 22: 746-752.

27. Oliveira EC, Ribeiro AL, Amaral CF. Adenosine for vasoreactivity testing in pulmonary hypertension: a head-to-head comparison with inhaled nitric oxide. Respir Med 2010; 104: 606-611.

28. Kao B, Balzer DT, Huddleston CB, Canter CE. Longterm prostacyclin infusion to reduce pulmonary hypertension in a pediatric cardiac transplant candidate prior to transplantation. J Heart Lung Transplant 2001; 20: 785-788.
29. Perez-Villa F, Cuppoletti A, Rossel V, Vallejos I, Roig E. Initial experience with bosentan therapy in patients considered ineligible for heart transplantation because of severe pulmonary hypetension. Clin Transplant 2006; 20: 239-244.

30. Liden H, Haraldsson A, Ricksten SE, Kjellman U, Wiklund L. Does pretransplant left ventricular assist device therapy improve results after heart transplantation in patients with elevated pulmonary vascular resistance? Eur J Cardiothorac Surg 2009; 35: 1029-1035.

31. Chen JM, Richmond ME, Charette K, et al. A decade of pediatric mechanical circulatory support before and after cardiac transplantation. J Thorac Cardiovasc Surg 2012; 143: 344-351.

32. Yilmaz B, Zuckerman WA, Lee TM, et al. Left ventricular assist device to avoid heartlung transplant in an adolescent with dilated cardiomyopathy and severely elevated pulmonary vascular resistance. Pediatr Transplant 2013; 17: E113-E116.

33. Ofori-Amanfo G, Hsu D, Lamour JM, et al. Heart transplantation in children with markedly elevated pulmonary vascular resistance: impact of right ventricular failure on outcome. J Heart Lung Transplant 2011: 30: 659-666.

34. Klotz S, Wenzelburger F, Stypmann J, et al. Reversible pulmonary hypertension in heart transplant candidates: to transplant or not to transplant. Ann Thorac Surg 2006: 82: 1770-1773.

35. Maxwell BG, Sheikh AY, Ajuba-Iwuji CC, Heitmiller ES, Vricella LA. Pulmonary vascular resistance index and mortality after paediatric heart transplant. Cardiol Young 2015; 25: 1141-1147. 